\title{
HCI Themes for the Future: Collaborative Design, Social Creativity, and Meta-design
}

\author{
Gerhard Fischer \\ Center for Lifelong Learning and Design University of Colorado, Boulder \\ gerhardecolorado.edu
}

\begin{abstract}
The participants will be acquainted with HCI themes for the future. These themes will be instantiated with new conceptual frameworks and illustrated with innovative systems. The presentation will be linked as much as possible to the concerns and experiences of the participants. The objective of the tutorial is to provide the participants with opportunities to think differently about the future challenges facing HCI research and practice and to illustrate with concrete examples how these challenges can be addressed.

The tutorial will focus on three major themes: (1) design, specifically collaborative design and an assessment of different design methodologies (including: user-centered design, learner-centered design, and participatory design); (2) social creativity which is required because complex design problems transcend the unaided, individual human mind; and (3) meta-design which creates environments involving users as active contributors rather than as passive consumers.

The themes of the tutorial will be illustrated with specific theoretical frameworks and innovative systems developed by the presenter and his colleagues and other research groups working on these topics. The relevance of these themes has been demonstrated by their impact on research, education, and design practices in companies, educational institutions, and research organizations with which we have collaborated.
\end{abstract}

\section{Summary of Contents}

The tutorial will discuss in depth fundamental problems facing $\mathrm{HCI}$ in the future. It will present conceptual frameworks, innovative systems, examples of new practices, and assessment efforts instantiating this vision. Evidence will be provided that system development is difficult not because of the complexity of technical problems, but because of the social interaction between different stakeholders as they learn to create, develop, and express their ideas and visions. It will introduce meta-design as a framework to create open systems in which users can modify and evolve the systems to fit their specific needs that could not be anticipated by the system developers at design time.

The tutorial will be centered on the specific, but integrated themes of "Collaborative Design, Social Creativity, and Meta-Design" representing a coherent vision for the future of HCI based on extensive research by the presenter and his colleagues at the University of Colorado, Boulder as well as in collaborations with other researchers and research centers around the world. It will explore major aspects about: 
1. design and collaborative design [Benkler, 2006; Simon, 1996]: (1) the importance of domain knowledge in design: domains are not natural, God-given entities, but they are part of the "sciences of the artificial" [Fischer, 1994]; and (2) the critical importance of evolutionary models in design: evolution is required by the fact that design often has to proceed without final goals and therefore has to cope with fluctuating and conflicting requirements. The seeding, evolutionary growth, reseeding process model will be presented which is able to cope with fluctuating and conflicting requirements.

2. social creativity: transcending the unaided individual human mind: the power of the unaided individual mind is highly overrated [Arias et al., 2000; Norman, 1993]. Although creative individuals are often thought of as working in isolation, much of our intelligence and creativity results from interaction and collaboration with other individuals [Shneiderman, 2002] [Csikszentmihalyi, 1996].

3. meta-design: empowering users to act as informed participants: meta-design [Fischer \& Giaccardi, 2006; Fischer et al., 2004] characterizes objectives, techniques, and processes for creating new media and environments that allow the owners of problems to act as designers contributing and benefiting from the creativity of all participants.

\section{References}

1. Arias, E.G., Eden, H., Fischer, G., Gorman, A., Scharff, E.: Transcending the Individual Human Mind: Creating Shared Understanding through Collaborative Design. ACM Transactions on Computer Human-Interaction 7(1), 84-113 (2000)

2. Benkler, Y.: The Wealth of Networks: How Social Production Transforms Markets and Freedom. Yale University Press, New Haven (2006)

3. Csikszentmihalyi, M.: Creativity - Flow and the Psychology of Discovery and Invention. HarperCollins Publishers, New York (1996)

4. Fischer, G.: Domain-Oriented Design Environments. Automated Software Engineering 1(2), 177-203 (1994)

5. Fischer, G., Giaccardi, E.: Meta-Design: A Framework for the Future of End User Development. In: Lieberman, H., Paterno, F., Wulf, V. (eds.) End User Development: Empowering people to flexibly employ advanced information and communication technology, pp. 427-458. Kluwer Academic Publishers, Dordrecht, The Netherlands (2006)

6. Fischer, G., Giaccardi, E., Ye, Y., Sutcliffe, A.G., Mehandjiev, N.: Meta-Design: A Manifesto for End-User Development. Communication of the ACM 47(9), 33-37 (2004)

7. Norman, D.A.: Things That Make Us Smart. Addison-Wesley Publishing Company, Reading (1993)

8. Shneiderman, B.: Leonardo's Laptop - Human Needs and the New Computing Technologies. MIT Press, Cambridge (2002)

9. Simon, H.A.: The Sciences of the Artificial. The MIT Press, Cambridge (1996) 